\title{
Primary cutaneous malignancies in the Northern Cape Province of South Africa: A retrospective histopathological review
}

\author{
K York, ${ }^{1} \mathrm{MB}$ BCh; N C Dlova, ${ }^{2} \mathrm{MB}$ ChB, FC Derm (SA), PhD; C Y Wright,${ }^{3} \mathrm{PhD}$; N P Khumalo, ${ }^{1} \mathrm{MB}$ ChB, FC Derm (SA), PhD; \\ P E Kellett, ${ }^{4} \mathrm{~N}$ Dip Med Tech; R Kassanjee, ${ }^{5} \mathrm{PhD}$; A Mosam, ${ }^{2} \mathrm{MB}$ ChB, FC Derm (SA), PhD \\ ${ }^{1}$ Department of Dermatology, Groote Schuur Hospital and Faculty of Health Sciences, University of Cape Town, South Africa \\ ${ }^{2}$ Department of Dermatology, School of Clinical Medicine, College of Health Sciences, Nelson R Mandela School of Medicine, University of \\ KwaZulu-Natal, Durban, South Africa \\ ${ }^{3}$ Environment and Health Research Unit, South African Medical Research Council and Department of Geography, Geoinformatics and \\ Meteorology, Faculty of Natural and Agricultural Sciences, University of Pretoria, South Africa \\ ${ }^{4}$ National Cancer Registry, National Health Laboratory Service, Johannesburg, South Africa \\ ${ }^{5}$ Department of Statistical Sciences, Faculty of Science, University of Cape Town, South Africa
}

Corresponding author: K York (kathyork20@gmail.com)

Background. Excessive sun exposure and a high prevalence of HIV increase skin cancer risk in South Africa (SA).

Objective. To describe the nature and extent of skin cancers presenting in the public and private health sectors of the Northern Cape Province of SA.

Methods. A retrospective analysis of histologically confirmed new primary cutaneous malignancies from 1 January 2008 to 31 December 2012 was conducted using public and private health sector databases. Types, quantity and distribution of common invasive malignancies by population group, age, gender, anatomical site and health sector were explored. One-year cumulative incidence was calculated and logistic regression models were used to analyse incidence and melanoma thickness trends.

Results. A total of 4270 biopsies (13 cutaneous malignancies) were identified. The commonest was squamous cell carcinoma (SCC), followed by basal cell carcinoma, Kaposi's sarcoma (KS), cutaneous malignant melanoma (CMM) and basosquamous carcinoma, in descending order. The odds of a white male developing SCC increased by $8 \%$ each year (odds ratio (OR) 1.08, 95\% confidence interval (CI) $1.01-1.15 ; p=0.022$ ), while the odds of a black male developing SCC and KS decreased by $9 \%$ (OR $0.91,95 \%$ CI $0.84-0.99 ; p=0.033$ ) and $18 \%$ (OR $0.82,95 \%$ CI $0.70-0.97 ; p=0.022)$, respectively, each year. SCC and CMM were diagnosed at more advanced stages in the public than in the private healthcare sector. CMM is being detected earlier, as indicated by low-stage depth increasing by $72 \%$ annually (OR $1.72,95 \%$ CI $1.04-3.01 ; p=0.042$ ).

Conclusions. Results suggest that reported skin cancer patterns are changing. There is a need for further research and equitable appropriation of financial resources and effort towards developing primary skin cancer prevention initiatives in SA.

S Afr Med J 2017;107(1):83-88. DOI:10.7196/SAMJ.2017.v107i1.10924

Because of its location, most parts of South Africa (SA) have high levels of solar ultraviolet radiation (UVR). ${ }^{[1]}$ Despite its geographical size, the Northern Cape (NC) Province has the smallest population of the provinces in SA, with only 1.18 million inhabitants, of whom $50.4 \%$ are black, $40.3 \%$ coloured, $7.1 \%$ white, $0.7 \%$ Indian/Asian and $1.5 \%$ other ${ }^{[2,3]}$ Its economy relies mainly on mining and agriculture, and almost one-fifth of the currently employed NC population work outdoors in the agricultural industry. ${ }^{[4]}$ Approximately $90 \%$ of nonmelanoma skin cancer (NMSC) is attributable to personal UVR exposure, so South Africans are especially susceptible to skin cancer owing to their year-round exposure to high ambient solar UVR. ${ }^{[5]}$ Individuals working in outdoor occupations are at an even greater risk of NMSC, as they are likely to be outside for more daylight hours. ${ }^{[6,7]}$ SA has one of the world's largest HIV epidemics, ${ }^{\left[{ }^{[}\right]}$with infected individuals having a 3 - 5-fold and 50-fold increased risk of developing NMSC and HIV-associated Kaposi's sarcoma (KS), respectively. ${ }^{[9]}$

The incidence of NMSC and cutaneous malignant melanoma (CMM) is increasing globally, so reporting systems to monitor numbers of cases and trends over time are essential. ${ }^{[10,11]}$ However, owing to limited private sector submissions to the National Cancer
Registry (NCR) the last comprehensive data inclusive of all health sectors were published in 2004, making it difficult to establish whether skin cancer incidence in SA has followed the global trend. ${ }^{[12]}$

In 2011, the SA National Department of Health passed a regulation ${ }^{[13]}$ that made cancer a reportable disease, requiring that all histologically confirmed cases be reported to the NCR. ${ }^{[14]}$ Concerns have been raised that if the incidence of skin cancer continues to rise unchecked, it may become a major health problem and place a large financial burden on private and public health services. ${ }^{[15]}$ Of additional concern is that melanomas of a depth $>4 \mathrm{~mm}$ carry a high risk of mortality. ${ }^{[16]}$ As tumour thickness provides an indication of how early a melanoma has been detected, monitoring trends in melanoma thickness to assess whether thinner melanomas are being detected may be appropriate. ${ }^{[17]}$

\section{Objective}

To describe the nature and extent of different types of histologically confirmed skin cancers presenting in the public and private health sectors of the NC to provide insight into the local skin cancer burden in SA. 


\section{Methods}

A retrospective chart review of histologically confirmed new primary cutaneous malignancies from 1 January 2008 to 31 December 2012 was conducted. Different types of skin cancer, numbers of each and the distribution of the five commonest invasive malignancies by population group, age, gender, anatomical site and health sector were explored. The incidences of the five most common invasive malignancies and their trends over 5 years were calculated. Trends in melanoma thickness were analysed.

Skin biopsies from public facilities in the NC are sent to the National Health Laboratory Service histopathology laboratory, while those from private facilities are sent to PathCare or Ampath laboratories. Data on all incident cases were extracted by performing a Systemised Nomenclature of Medicine (SNOMED) search of the Laboratory of Data Intensive Systems and Applications (DISA), PathCare and Ampath databases, using the SNOMED codes for all cutaneous malignancies. The data extracted from the histopathology reports for each patient included the date, histopathological diagnosis, population group, gender, age, anatomical site of the lesion and health sector. The study was conducted in accordance with ethical principles contained in the Declaration of Helsinki. ${ }^{[18]}$ It was approved by the Faculty of Health Sciences Ethics Committee of the University of Cape Town (HREC/REF: 357/2015).

All histologically confirmed new primary cutaneous malignancies in public and private sector paediatric and adult patients from towns in the NC between the study dates were eligible to be included. Exclusion criteria included new primary cutaneous malignancies that were not incident cases, cutaneous metastases, squamous cell carcinoma (SCC) of the tongue, palate, buccal mucosa, vagina and anus, and KS of the tonsil, tongue, larynx and nasopharynx.

\section{Statistical analysis}

Before analysing the data, the Data Management and Statistical Analysis Unit of the University of the Witwatersrand, Johannesburg, used a hot-deck imputation method to correlate cases with no population group against a reference database containing surnames with a known population group. This enabled each patient's population group to be estimated, as was done by the NCR in 1998 when it faced a similar dilemma. The method proved to be accurate, and its results compared well with previous registry statistics. ${ }^{[19-21]}$

For the primary analysis, two software packages were used, namely SPSS Statistics version 21 (IBM, USA) and R version 3.1.3, 64-bit version ( $\mathrm{R}$ Foundation for Statistical Computing, Austria). The statistical analysis was divided into three components.

The first component involved establishing the main types of skin cancer according to patient demographic and histological data. Empirical descriptive statistics were calculated. The Kruskal-Wallis test for similarities in age distribution between different types of cutaneous malignancies was performed because the data were not normally distributed.

The second component involved calculating the incidences of the five most common cutaneous malignancies for each year. Throughout this article, incidence refers to yearly cumulative incidence, i.e. the proportion of those at risk who acquire cancer over a 1-year period. The incidence of each malignancy was calculated using the total number of new histologically confirmed cases of a skin cancer type in a particular year as the numerator, with the NC mid-year population estimate for the year as the denominator. This was reported as incidence per 100000 per year.

The third component investigated trends in incidence and melanoma thickness over the 5 years. Logistic regression modelling was used to estimate annual incidence trends controlling for potential confounders.
The Hochberg procedure was used to adjust for multiple comparisons. The level of significance was set at a two-sided $p$-value $(p<0.05)$. To investigate trends in melanoma thickness over 5 years, Clark's staging data were collapsed into 'high-stage' and 'low-stage' categories for analysis, 'low stage' being Clark levels 1 and 2 and 'high stage' Clark levels 3 - 5. Odds ratios (ORs) for a low stage were estimated using logistic regression modelling adjusted for potential confounders.

\section{Results}

A total of 4270 biopsies comprising 13 cutaneous malignancies were identified. The five most common invasive malignancies made up $82.7 \%$ of all the cases. In descending order they were SCC, basal cell carcinoma (BCC), KS, CMM and basosquamous carcinoma (BSC) (Table 1).

\section{Demographics of the five most common invasive skin cancers}

Of the patients, 2093 (52.0\%) were white, 1047 (26.0\%) black, 864 $(21.4 \%)$ coloured and $23(0.6 \%)$ Indian/Asian. Imputed population group was unspecified in 243 patients. BCC, CMM and BSC occurred relatively more frequently in white individuals than in other population groups. A high rate of SCC was observed in white, black and coloured individuals. KS occurred more commonly in the black population (Fig. 1).

The male/female ratio was 1:1 (2 108 males, 2095 females). Gender was unspecified in 67 patients. All five of the most common invasive cutaneous malignancies affected males more frequently than females, with BSC occurring twice as often in males. Squamous cell carcinoma in situ (SCCI) represented the major exception to this trend, occurring six times more frequently in females (Fig. 2).

Age range spanned 2 - 101 years (mean 51.6). There was a statistically significant difference in age distribution between malignancies $(p<0.001)$. BCC occurred most frequently in the age group 60 - 69 years, while CMM and SCC presented most commonly in those aged 50 - 59 years and BSC in those aged $70-79$ years. The majority of KSs occurred in the younger age group $30-39$ years.

Table 1. Skin cancer spectrum and distribution

\begin{tabular}{ll}
\hline Skin cancer types & $\boldsymbol{n}(\%)$ \\
\hline Squamous cell carcinoma & $1938(45.4)$ \\
Basal cell carcinoma & $1185(27.8)$ \\
Squamous cell carcinoma in situ & $667(15.6)$ \\
Kaposi's sarcoma & $276(6.5)$ \\
Cutaneous malignant melanoma & $135(3.1)$ \\
Basosquamous carcinoma & $43(1.0)$ \\
Dermatofibrosarcoma protuberans & $13(0.3)$ \\
Mycosis fungoides & $3(0.07)$ \\
Sebaceous adenocarcinoma & $3(0.07)$ \\
Trichilemmal carcinoma & $3(0.07)$ \\
Angiocentric T-cell lymphoma & $2(0.05)$ \\
Merkel cell carcinoma & $1(0.02)$ \\
Mucinous carcinoma & $1(0.02)$ \\
Total & $4270(100)$
\end{tabular}




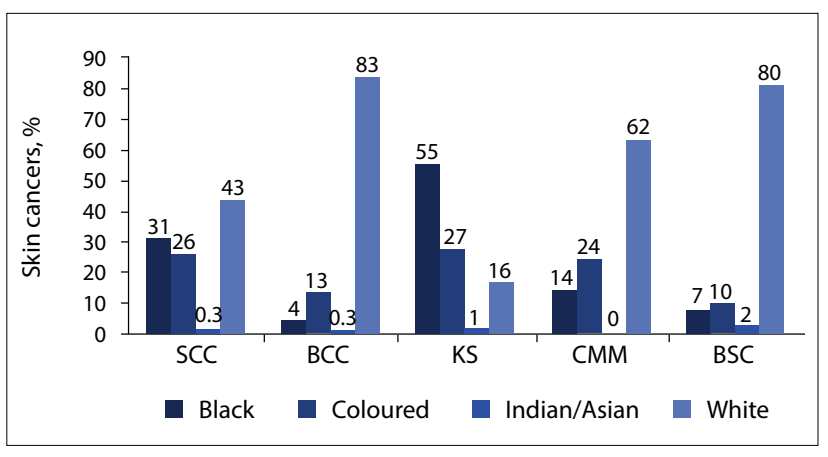

Fig. 1. Skin cancer distribution according to population group.

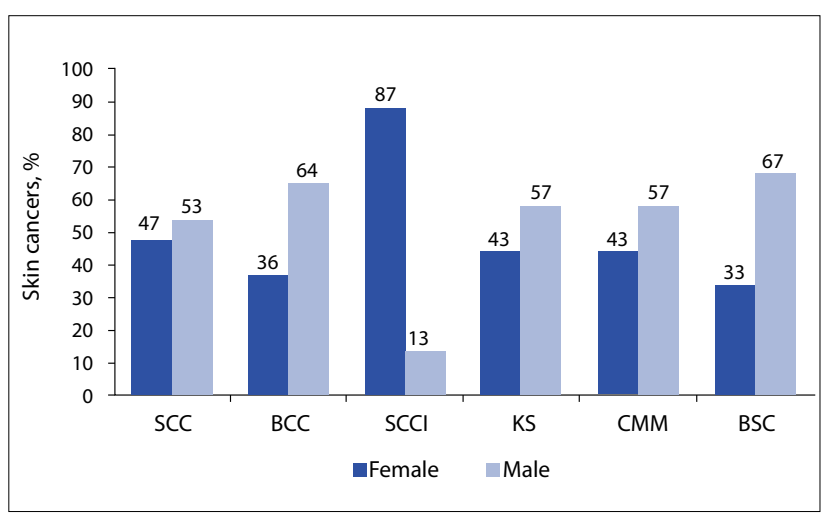

Fig. 2. Skin cancer distribution according to gender.

Head and neck regions were the most common anatomical sites affected by BCC, SCC and BSC. CMM occurred most commonly on the lower limbs.

Of the 4270 biopsies, 2448 (57.3\%) and 1822 (42.7\%) were from the public and private healthcare sectors, respectively. In decreasing order of frequency, BCC, SCC and CMM were most common in the private sector, while SCC followed by KS accounted for the majority of the pathology in the public sector (Fig. 3). Ninety percent ( $n=1061)$ of the BCCs occurred in private sector patients, while $73.1 \%(n=1417)$ of SCCs identified were from the public sector. Of the 101 patients with CMM, 62.4\% ( $n=63)$ were from the private sector while $37.6 \%(n=38)$ were from the public sector. Of the private sector patients $83.7 \%$ were white, while in the public sector $27.3 \%$ were white, $43.0 \%$ black and $28.9 \%$ coloured (Table 2 ).

Of the invasive SCCs, 1524 (78.6\%) could be categorised according to tumour differentiation. Of these, $20.9 \%$ were well differentiated, while $58.9 . \%$ were moderately differentiated and $20.2 \%$ were poorly differentiated. In both the coloured and black populations, almost a quarter of malignancies were poorly differentiated.

\section{Incidence and 5-year incidence trends}

Table 3 reports the incidence of the five most common invasive cutaneous malignancies (/100 000) from 2008 to 2012, as well as the estimated ORs of each cancer for a 1-year increase. Incidence was then plotted and logistic regression was used to model trends. Categories marked with an asterisk in Table 3 are those in which a significant trend $(p<0.05)$ was seen (Fig. 4$)$.

The odds of a black male developing KS or SCC decreased by $18 \%$ (OR 0.82, 95\% confidence interval (CI) $0.70-0.97 ; p=0.0222$ ) and $9 \%$ (OR 0.91, 95\% CI $0.84-0.99 ; p=0.0336$ ), respectively, every year over the 5 -year period. In contrast, the odds of a white male developing BSC or SCC increased by $45 \%$ (OR 1.45, 95\% CI 1.08 1.99; $p=0.0177)$ and $8 \%$ (OR 1.08, 95\% CI $1.01-1.15 ; p=0.0225)$,

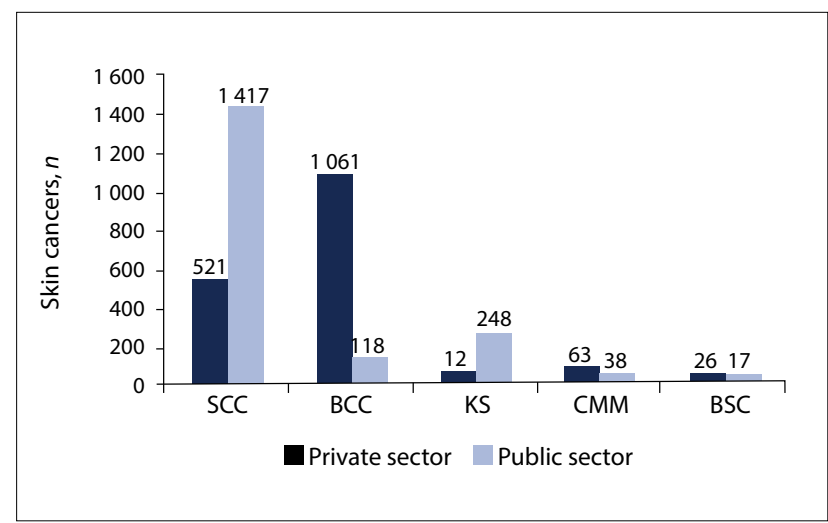

Fig. 3. Skin cancer distribution according to health sector.
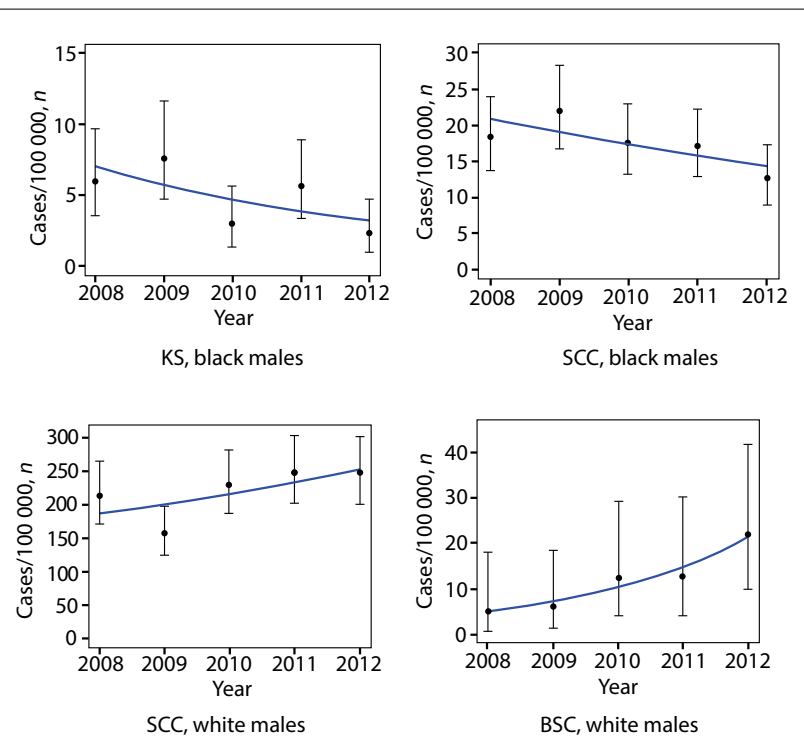

Fig. 4. Significant changes in incidence trends, 2008 - 2012.

Table 2. Population group distribution in the private and public sectors

\begin{tabular}{lll}
\hline Population group & Private sector, $\boldsymbol{n}(\%)$ & Public sector, $\boldsymbol{n}(\%)$ \\
\hline Black & $71(4.0)$ & $976(43.0)$ \\
Coloured & $209(11.9)$ & $655(28.9)$ \\
Indian & $5(0.3)$ & $18(0.8)$ \\
White & $1473(83.7)$ & $620(27.3)$ \\
Total & $1758(100)$ & $2269(100)$ \\
$\begin{array}{l}{ }^{*} \text { Imputed population group unspecified for } 64 \text { and } 179 \text { patients in the private and public } \\
\text { sectors, respectively. }\end{array}$
\end{tabular}

respectively. Once the Hochberg procedure was applied, significant trends in incidence were not observed.

\section{Trends in melanoma thickness}

Of CMMs, $55.4 \%$ were not subtyped and $25.7 \%$ were still in the in situ phase at the time of excision. Acral lentiginous melanoma (ALM) was the subtype that occurred most frequently, and all cases of this subtype occurred in the public sector. Clark level for $\mathrm{CMM}$ in the private sector ranged from 1 to 4 (mean 2.7), while 
Table 3. Incidence of malignancies from 2008 to 2012 and estimated ORs for a 1-year time increase

\begin{tabular}{|c|c|c|c|c|c|c|c|c|c|c|c|c|}
\hline \multirow[b]{2}{*}{ Cancer } & \multirow[b]{2}{*}{ Gender } & \multirow[b]{2}{*}{ Race } & \multicolumn{5}{|c|}{ Incidence, 100 000/year } & \multicolumn{3}{|c|}{ OR } & \multicolumn{2}{|c|}{$p$-values } \\
\hline & & & 2008 & 2009 & 2010 & 2011 & 2012 & Est. & $\begin{array}{l}95 \% \text { CI } \\
\text { LL }\end{array}$ & $\begin{array}{l}95 \% \text { CI } \\
\text { UL }\end{array}$ & Adj. & Unadj. \\
\hline \multirow[t]{6}{*}{ SCC } & $\mathrm{F}$ & B & 19 & 19.6 & 13.8 & 18.5 & 15.6 & 0.96 & 0.88 & 1.04 & 0.9852 & 0.2787 \\
\hline & & $\mathrm{C}$ & 17.3 & 19.7 & 19.7 & 34.6 & 16 & 1.05 & 0.96 & 1.15 & 0.9852 & 0.2731 \\
\hline & & $\mathrm{W}$ & 142.2 & 143.4 & 145.2 & 186.6 & 115 & 1 & 0.92 & 1.08 & 0.9852 & 0.9429 \\
\hline & M & B & 18.3 & 21.9 & 17.5 & 17.1 & 12.6 & $0.91^{*}$ & $0.84^{*}$ & $0.99^{*}$ & $0.9074^{*}$ & $0.0336^{*}$ \\
\hline & & $\mathrm{C}$ & 19.2 & 24.8 & 23.4 & 21.35 & 23.5 & 1.02 & 0.93 & 1.12 & 0.9852 & 0.6523 \\
\hline & & $\mathrm{W}$ & 215 & 158.3 & 230 & 248.7 & 248 & $1.08^{*}$ & $1.01^{*}$ & $1.15^{*}$ & $0.6308^{*}$ & $0.0225^{\star}$ \\
\hline \multirow[t]{6}{*}{ BCC } & F & B & 0.3 & 0.6 & 1.47 & 0.84 & 0.63 & 1.13 & 0.76 & 1.70 & 0.9852 & 0.5456 \\
\hline & & C & 5.7 & 3.9 & 4.8 & 6.9 & 6.1 & 1.06 & 0.89 & 1.27 & 0.9852 & 0.4851 \\
\hline & & W & 157.7 & 108.6 & 166.6 & 171.1 & 185 & 1.08 & 1 & 1.16 & 0.9852 & 0.0532 \\
\hline & $\mathrm{M}$ & B & 2.1 & 1.8 & 1.6 & 1.86 & 2.9 & 1.09 & 0.85 & 1.41 & 0.9852 & 0.5189 \\
\hline & & C & 6.1 & 8.9 & 6.3 & 11.9 & 8.3 & 1.09 & 0.94 & 1.27 & 0.9852 & 0.2709 \\
\hline & & $\mathrm{W}$ & 295 & 208 & 327.5 & 346.1 & 295 & 1.05 & 0.99 & 1.11 & 0.9852 & 0.0756 \\
\hline \multirow[t]{6}{*}{ KS } & $\mathrm{F}$ & B & 3.93 & 4.22 & 4.12 & 2.53 & 2.22 & 0.86 & 0.71 & 1.04 & 0.9852 & 0.1138 \\
\hline & & C & 4 & 2.63 & 2.4 & 2.47 & 1.29 & 0.80 & 0.60 & 1.46 & 0.9852 & 0.0998 \\
\hline & & W & 8.19 & 4.34 & 7.14 & 8.19 & 7.5 & 1.03 & 0.72 & 1.46 & 0.9852 & 0.8858 \\
\hline & $\mathrm{M}$ & B & 5.98 & 7.55 & 2.93 & 5.59 & 2.26 & $0.82^{*}$ & $0.70^{*}$ & $0.97^{*}$ & $0.6308^{*}$ & $0.0222^{\star}$ \\
\hline & & C & 3.55 & 1.87 & 2.44 & 7.29 & 2.3 & 1.08 & 0.85 & 1.37 & 0.9852 & 0.5243 \\
\hline & & W & 12.5 & 6.25 & 12.5 & 7.69 & 9.75 & 0.97 & 0.70 & 1.32 & 0.9852 & 0.8328 \\
\hline \multirow[t]{6}{*}{ CMM } & F & B & 0.61 & 0.60 & 0.58 & 0.28 & 0.63 & 0.95 & 0.58 & 1.52 & 0.9852 & 0.8186 \\
\hline & & C & 0.44 & 0.43 & 1.92 & 0 & 0.43 & 0.94 & 0.54 & 1.59 & 0.9852 & 0.8107 \\
\hline & & $\mathrm{W}$ & 11.1 & 4.34 & 14.2 & 4.4 & 25 & 1.26 & 0.95 & 1.70 & 0.9852 & 0.1130 \\
\hline & $\mathrm{M}$ & B & 0.35 & 0.35 & 0 & 0.31 & 0 & 0.68 & 0.24 & 1.55 & 0.9852 & 0.3836 \\
\hline & & $\mathrm{C}$ & 1.01 & 2.81 & 1.95 & 1.04 & 0.46 & 0.81 & 0.55 & 1.16 & 0.9852 & 0.2578 \\
\hline & & $\mathrm{W}$ & 12.5 & 16.6 & 15 & 17.9 & 17.1 & 1.07 & 0.83 & 1.36 & 0.9852 & 0.6109 \\
\hline \multirow[t]{6}{*}{ BSC } & F & B & 0 & 0.3 & 0 & 0 & 0 & 0.56 & 0.04 & 2.54 & 0.9852 & 0.5037 \\
\hline & & C & 0.44 & 0 & 0.48 & 0 & 0 & 0.58 & 0.17 & 1.35 & 0.9852 & 0.2631 \\
\hline & & W & 2.22 & 2.17 & 9.5 & 2.22 & 5 & 1.15 & 0.72 & 1.88 & 0.9852 & 0.5620 \\
\hline & $\mathrm{M}$ & B & 0 & 0 & 0 & 0.62 & 0 & 1.72 & 0.60 & 8.83 & 0.9852 & 0.3730 \\
\hline & & C & 0.51 & 0 & 0 & 0 & 0.46 & 0.99 & 0.34 & 2.89 & 0.9852 & 0.9852 \\
\hline & & $\mathrm{W}$ & 5 & 6.25 & 12.5 & 12.8 & 21.9 & $1.45^{*}$ & $1.08^{*}$ & $1.99^{*}$ & $0.5299^{*}$ & $0.0177^{*}$ \\
\hline
\end{tabular}

in the public sector it ranged from 2 to 5 (mean 4.2). Only in 2012 were no cases with a Clark level 5 seen. Once Clark's staging data were collapsed into low and high stages and a logistic regression model was applied, the OR for low-stage depth for every 1-year increase from 2009 to 2012 was estimated to be 1.72 (95\% CI 1.04 $3.01 ; p=0.0429)$. This indicates that the odds of a low-stage depth increased by $72 \%$ from one year to the next, confirming that CMM is being detected earlier.

\section{Discussion}

SCC, BCC, KS and CMM were the four most frequently occurring skin cancers in the $\mathrm{NC}$, in accordance with the 2004 national statistics published by the NCR. ${ }^{[2]}$ SCC was the most frequent cutaneous malignancy seen between 2008 and 2012, and high rates were observed in the white, black and coloured population groups. The incidence of SCC has risen worldwide over the past several decades, at an estimated $3-10 \%$ per year. ${ }^{[23]}$ The vast majority of NMSC is attributed to personal UVR exposure, and SA is located in the southern hemisphere, which has a greater intensity of UVR than northern hemisphere sites at a similar latitude. ${ }^{[1,24]}$ Another contributor may be that $18.5 \%$ of the currently employed NC population works in the agricultural industry, ${ }^{[4]}$ which is more than double the proportion of the population doing so in any other province. Individuals who work outdoors have a $43 \%$ and $77 \%$ increased risk of BCC and SCC, respectively. ${ }^{[6,7]}$ In addition, the prevalence of HIV infection in the NC in 2011 was $17 \%,{ }^{[25]}$ and individuals with this disease have an increased risk of developing NMSC. ${ }^{[8]}$ The HIV status of the patients included in this study was 
unknown, but infection with the virus may have contributed to the high observed SCC incidence.

SCC and BCC tend to occur more frequently in males, ${ }^{[26]}$ and this study found this observation to be true (male/female ratio 1.1:1 for SCC and 1.7:1 for BCC). Approximately 75\% of SCCI occurs in women, ${ }^{[27]}$ but an even higher rate $(87.0 \%)$ was seen here.

A sharp increase in BCC incidence was seen in the age group $>60$ years. The majority of SCC developed in a younger age group (50 - 59 years) than that in which it is normally seen. ${ }^{[26]}$ The SA data from 2000 to 2004 found SCC in the black population also to be developing about 10 years earlier. ${ }^{[28]} \mathrm{HIV}$ infection and the large percentage of the NC population working outdoors in the agricultural industry from a young age were likely to have contributed to the earlier presentation of SCC observed in this study. The KSs observed were probably of the AIDS-related type, hence KS was used as a proxy for HIV status. The 2012 South African National HIV Prevalence, Incidence and Behaviour Survey ${ }^{[29]}$ found that females aged 30 - 34 years and males aged 35 - 39 years had the highest HIV infection rates, so it is not surprising that the incidence of KS in our study peaked in the age group 30 - 39 years.

The population group distribution in each health sector is likely to have influenced the range of malignancies seen within them. White individuals made up the majority of private sector patients, and it can be assumed that they would have a skin type I, II or III on the Fitzpatrick phototype classification scale. ${ }^{[30]}$ This may explain the predominant pathology seen the private sector, which in decreasing order included BCC, SCC and CMM. Black patients made up nearly half of public sector patients. SCC and KS are reportedly the most common cutaneous malignancies in black individuals, which may explain why these pathologies accounted for most skin cancer in the public sector. ${ }^{[31,32]}$

Poorly differentiated SCC occurred in a higher percentage of black and coloured individuals than white individuals. Poorly differentiated subtypes have a poorer prognosis and tend to be seen in patients who have presented late, once the tumour is already advanced. ${ }^{[33]}$ An explanation for the high frequency of this subtype in individuals with dark skins may be their lower perceived risk of skin cancer.

Between 2008 and 2012, the odds of a black male developing KS or SCC decreased significantly. A possible explanation for this decline may be that the roll-out of antiretroviral therapy (ART) in the NC only commenced in July 2004, at which time only $6.6 \%$ of HIV-positive patients requiring ART were receiving it. ${ }^{[34]}$ In contrast, by $2008,90.4 \%$ of these individuals were receiving ART. ${ }^{[34]}$ Most of the increase in CD4 count after starting ART occurs in the first 3 years. ${ }^{[35]}$ As the incidence of both SCC and KS is influenced by HIV and immune status, improvement in many individuals' immune status following ART initiation after 2004 may explain the declining rates of these pathologies a few years later. ${ }^{[9]}$ The rising incidences of BCC and SCC among white males between 2008 and 2012 concur with a recent systematic review of the global incidence of NMSC, which found an increase in its incidence in white populations worldwide. ${ }^{[10]}$

No significant trend in the incidence of CMM was seen in any race or gender group between 2008 and 2012. ALM was the subtype most commonly observed, all cases occurred in the public sector, and the majority were of an advanced depth (mean Breslow depth $4.13 \mathrm{~mm}$ ). A Breslow depth of $\geq 4 \mathrm{~mm}$ implies a 5 -year survival rate of $37-50 \% .{ }^{[16]}$ ALMs are often diagnosed at an advanced stage because it is difficult to distinguish them from ethnic pigmentation or traumatic skin changes. In addition, most practitioners have an increased threshold for performing biopsies in acral sites owing to associated delayed healing times and morbidity. CMMs in the public sector were diagnosed at a more advanced stage. Socioeconomic factors influence disease outcomes in CMM, and less affluent groups generally have more advanced disease and poorer survival rates. ${ }^{[36]}$ In addition to the abovementioned factors, longer waiting times for appointments in the public sector may impact on late diagnosis. Tumour thickness is an indicator of the effectiveness of early detection of melanomas, ${ }^{[17]}$ and in many countries there is an ongoing trend towards earlier detection and therefore thinner melanomas being discovered, as well as an increase in the percentage of melanoma in situ diagnosed. ${ }^{[17]}$ The fact that one-quarter of melanomas in our study were still in the in situ phase at the time of excision, and that the odds of a low-stage depth were found to increase from one year to the next, confirmed that CMMs in the NC are also being detected at an earlier stage.

\section{Study limitations}

Study limitations included using only histologically confirmed cases of skin cancer. Some malignancies (e.g. BCC or KS) may have been diagnosed on the basis of characteristic clinical features and treated without histological confirmation, resulting in underestimation of the true cumulative incidence. The sparsely populated NC is a large province, and is bordered by Namibia, Botswana, and other provinces of SA. ${ }^{[37]}$ It is possible that some individuals may have sought treatment for suspicious skin lesions in other countries or provinces, and this may have led to skewing of the figures. HIV status of participants in the study was unknown. As HIV increases the risk of developing an NMSC, ${ }^{[9]}$ this may have influenced the incidence of NMSC observed. Very little patient history was supplied on the majority of histopathology request forms, and this was a limitation with regard to SCC, as it was not possible to tell whether the malignancy had arisen in a scar or chronic ulcer or on sun-exposed skin. There are no NC skin cancer statistics to refer to or compare with, so comparisons with previous national skin cancer statistics had to be made.

\section{Conclusions}

This is the first SA study to collate and analyse public and private sector skin cancer data for an entire province. These data give insight into the skin cancer burden faced by the NC and provide a basis for future monitoring of skin cancer incidence. They also supply a framework to measure effectiveness of skin cancer prevention programmes in the province. Skin cancer patterns in SA are changing. There is a need for equitable appropriation of greater financial resources and effort towards developing primary prevention initiatives tailored to an SA context, in order to curb further increases in skin cancer incidence.

Author contributions. NCD and AM made substantial contributions to the conception and design of the study and revised the manuscript critically. KY drafted the manuscript and acquired and interpreted the data. NPK assisted with interpretation and presentation of the data and revised the manuscript critically for intellectual content. RK implemented statistical analyses and assisted with presentation and interpretation of the results. CYW and PEK advised during the course of the study, and CYW assisted with manuscript preparation for submission.

Acknowledgements. The Department of Medicine at the University of Cape Town (UCT) supplied funding for payment of the UCT Department of Statistical Sciences for their assistance with the statistical analysis. The authors acknowledge the support provided by the consulting service at the department. Maureen Krige is acknowledged for editing the manuscript. 
1. Roy C, Gies H, Toomey S. The solar UV radiation environment: Measurement techniques and results. J Photochem Photobiol B 1995;31(1-2):21-27. http://dx.doi.org/10.1016/1011-1344(95)07164-8

2. Statistics South Africa. Mid-year Population Estimates 2015. Pretoria: SSA, 2015. https://www.statssa gov.za/publications/P0302/P03022015.pdf (accessed 30 January 2016).

3tatistics South Africa. Census 2011. Pretoria: SSA, 2012. http://www.statssa.gov.za/publications P03014/P030142011.pdf (accessed 20 August 2016).

4. Statistics South Africa. National and Provincial Labour Market Trends, 2003-2013. Pretoria: SSA, 2013 http://beta2.statssa.gov.za/publications/P02114/P021142013.pdf (accessed 30 January 2016).

5. Wright C, Norval M, Summers B, Davids L, Coetzee G, Oriowo M. Solar ultraviolet radiation exposure and human health in South Africa: Finding a balance. S Afr Med J 2012;102(8):665-666. http://dx.doi org/10.7196/SAMJ.5921

6. Bauer A, Diepgen T, Schmitt J. Is occupational solar ultraviolet irradiation a relevant risk factor for basal cell carcinoma? A systematic review and meta-analysis of the epidemiological literature. $\mathrm{Br}$ Dermatol 2011;165(3):612-625. http://dx.doi.org/10.1111/j.1365-2133.2011.10425x

7. Schmitt J, Seidler A, Diepgen T, Bauer A. Occupational ultraviolet light exposure increases the risk for the development of cutaneous squamous cell carcinoma. A systematic review and meta-analysis. Br J Dermatol 2011;164(2):291-307. http://dx.doi.org/10.1111/j.1365-2133.2010.10118.x

UNAIDS. Report on the Glabal AIDS Epidemic: Executive Summary. Geneva UNAIDS, 2006. http:/ww unaids.org/sites/default/files/media_asset/2006_gr-executivesummary_en_0.pdf (accessed 30 January 2016).

9. Nthumba P, Cavadas P, Landin L. Primary cutaneous malignancies in sub-Saharan Africa. Ann Plast Surg 2011;66(3):313-320. http://dx.doi.org/10.1097/SAP.0b013e318 1e7db9a

10. Lomas A, Leonardi-Bee J, Bath-Hextall F. A systematic review of worldwide incidence of nonmelanom skin cancer. Br J Dermatol 2012;166(5):1069-1080. http://dx.doi.org/10.1111/j.1365-2133.2012.10830.x

11. Parkin D, Bray F, Ferlay J, Pisani P. Estimating the world cancer burden: Globocan 2000. Int J Cancer 2001;94(2):153-156. http://dx.doi.org/10.1002/ijc.1440

12. Singh E, Ruff P, Babb C, Sengayi M, Beery M, Khoali L. Establishment of a cancer surveillance programme: The South African experience. Lancet Oncol 2015;16(8):e414-e421. http://dx.do org/10.1016/S1470-2045(15)00162-X

13. Department of Health, South Africa. Regulations Relating to Cancer Registration. Pretoria: National Institute for Occupational Health, 2011 http./www govza/sites/www.gov.za/files/34248_rg9527 gon380.pdf (accessed 30 January 2016).

14. Tennessee Department of Health. Reportable Versus Notifiable. Tennessee. Johnson City, Tenn. Tennessee Department of Health, 2014. https://apps.health.tn.gov/ReportableDiseases/Common/ Tennessee Department of Health, 2014. https://apps.health.tn.gov/ReportableDisens

15. Gordon L, Elliot T, Wright C, Deghaye N, Visser W. Modelling the healthcare costs of skin cancer in South Africa. BMC Health Serv Res 2016;16:113. http://dx.doi.org/10.1186/s12913-016-1364-z

16. Melanoma Research Foundation. Melanoma Pathology - Understanding the Report. Washington, DC Melanoma Research Foundation, 2013. http://www.melanoma.org/understan-melanoma/diagnosingmelanoma/melanoma (accessed 30 January 2016)

7. Diepgen T, Mahler V. The epidemiology of skin cancer. Br J Dermatol 2002;146(Suppl 61):1-6. http:// dx.doi.org/10.1046/j.1365-2133.146.s61.2.x

18. World Medical Association. World Medical Association Declaration of Helsinki. Ethical Principles for Medical Research Involving Human Subjects. JAMA 2013;310(20):2191-2194. http://dx.doi org $/ 10.1001 / \mathrm{jama} .2013 .281053$

19. Mqoqi N, Kellet P, Sitas F. Incidence of Histologically Diagnosed Cancer in South Africa, 1998 1999. Johannesburg. National Cancer Registry, 2004. http //www cansa org za/files/2012/05/cancerstatistics-1998.pdf (accessed 30 January 2016).

20. Little R, Rubin D. The analysis of social science data with missing values. In: Fox J, ed. Modern Methods of Data Analysis. London: Sage Publications, 1990:292-326.
21. Singh E, Greyling M. A review of hot deck imputation for survey non response: The example of population group in the national cancer registry database. Presented at the 10th International Conference population group in the national cancer registry database. Presented at the 10th International Conference
on Cancer in Africa, Morocco, 18 November 2015. http://aorticconference.org/aortic2015.org/wpcontent/uploads/2015/11/2015-AORTIC-Abstract-Publication.pdf (accessed 30 January 2016).

22. National Cancer Registry. Cancer in South Africa 2004 Summary. Johannesburg: National Institute . National Cancer Registry. Cancer in South Africa 2004 Summary. Johannesburg: National Institute
for Occupational Health, 2004. http://www.nioh.ac.za/assets/files/2004-CancerReport-Summary.pdf (accessed 30 January 2016)

23. Demers A, Nugent Z, Mihalcioiu C. Trends in nonmelanoma skin cancer from 1960 through 2000 in a Canadian population. J Am Acad Dermatol 2005;53(2):320-328. http://dx.doi.org/10.1016/j. jaad.2005.03.043

24. Koh H, Geller A, Miller D, Grossbart T, Lew R. Prevention and early detection strategies for melanoma and skin cancer: Current status. Arch Dermatol 1996;132(4):436-443. http://dx.doi.org/10.1001/ archderm.1996.03890280098014

25. Statistics South Africa. 2011 Mid Year Population Estimates. Pretoria: SSA, 2011. http://www.statssa. gov:Za/publications/P0302/P03022011.pdf (accessed 30 January 2016).

26. Harris R, Griffith K, Moon T. Trends in the incidence of non melanoma skin cancers in southeastern Arizona, 1985-1996. J Am Acad Dermatol 2001;45(4):528-536. http://dx.doi.org/10.1067/ mjd.2001.114742

27. Primary Care Dermatology Society. Bowens Disease 2011. Hatfield, UK: Primary Care Dermatology Society, 2014. http://www.pcds.org.uk/clinical-guidance/bowens-disease (accessed 30 January 2016).

28. Norval M, Kellet P, Wright $C$. The incidence and body site of skin cancers in the popuations groups of South Africa. Photodermatol Photoimmunol Photomed 2014;30(5):262-265. http://dx.doi.org/10.1111/ phpp. 12106

29. Shisana O, Rehle T, Simbayi L, Zuma K, Jooste S, Zungu S. South African National HIV Prevalence, Incidence and Behaviour Survey, 2012. Cape Town: Human Sciences Research Council, 2014. http:// www.hsrc.ac.za/en/research-data/view/6871 (accessed 30 January 2016).

30. Fitzpatrick T. Soleil et peau. J Med Esthet 1975;2:33-34.

31. Ochicha O, Edino S, Mohammed A, Umar A. Dermatological malignancies in Kano, northern Nigeria: A histopathological review. Ann Afr Med 2004;3(4):188-191. http://dx.doi.org/10.4314/thrb.v14i1.3

32. Halder R, Bridgeman-Shah S. Skin cancer in African Americans. Cancer 1995;75(2 Suppl):667-673. http://dx.doi.org/10.1002/1097-0142(19950115)75

33. Rowe D, Carroll R, Day C. Prognostic factors for local recurrence, metastasis and survival rates in squamous cell carcinoma of the skin, ear and lip: Implication for treatment modality selection. J Am Acad Dermatol 1992;26(6):976-990.

34. South African National AIDS Council. HIV \& AIDS and STI National Strategic Plan, 2007 2011. South Africa: South African National AIDS Council, 2009. http://data.unaids.org/pub/ ExternalDocument/2007/20070604_sa_nsp_final_en.pdf (accessed 30 January 2016).

35. Lok J, Bosch R, Benson C, Collier A. Long-term increase in CD4+ T-cell counts during combination antiretroviral therapy for HIV-1 infection. AIDS 2011;24(12):1867-1876. http://dx.doi.org/10.1097/ QAD.0b013e32833adbcf

36. MacKie R, Hole D. Incidence and thickness of primary tumours and survival of patients with cutaneous malignant melanoma in relation to socioeconomic status. BMJ 1996;312(7039):1125-1128. http://dx.doi.org/10.1136/bmj.312.7039.1125

37. SouthAfrica.info. The nine provinces of South Africa. 2015. http://www.southafrica.info/about/ geography/ (accessed 30 January 2016).

Accepted 29 August 2016. 